\title{
LC-MS/MS Method for the Simultaneous Determination of Free Urinary Steroids
}

\author{
Fidel Allende $\cdot$ Sandra Solari $\cdot$ Carmen Campino $\cdot$ \\ Cristian A. Carvajal $\cdot$ Carlos F. Lagos $\cdot$ Andrea Vecchiola $\cdot$ \\ Carolina Valdivia · René Baudrand · Gareth I. Owen · Carlos E. Fardella
}

Received: 17 October 2013 / Revised: 20 January 2014 / Accepted: 22 January 2014 / Published online: 11 February 2014

(C) Springer-Verlag Berlin Heidelberg 2014

\begin{abstract}
Cortisol homeostasis is implicated in hypertension and metabolic syndrome. Two enzymes modulate cortisol availability; $11 \beta$-hydroxysteroid dehydrogenase type 1 (11 $\beta$-HSD1) preferentially converts inactive cortisone to cortisol, whereas $11 \beta$-hydroxysteroid dehydrogenase type 2 (11/-HSD2) converts cortisol to cortisone. In contrast, $5 \alpha$ and $5 \beta$ reductases inactivate cortisol by conversion to its tetrahydrometabolites: tetrahydrocortisol, allo-tetrahydrocortisol and tetrahydrocortisone. A subtle local increase in cortisol can be detected by measuring 24-h urine metabolites, LC-MS/MS being the reference method. The $11 \beta$ HSD2 activity is assessed based on the cortisol/cortisone ratio, and the $11 \beta$-HSD1 activity on the (tetrahydrocortisol + allo-tetrahydrocortisol)/tetrahydrocortisone ratio. To better understand hypertension and/or metabolic syndrome pathogenesis a method for simultaneous determination
\end{abstract}

F. Allende $\cdot$ S. Solari $(\bowtie)$

Departamento de Laboratorios Clínicos, Facultad de Medicina, Pontificia Universidad Católica de Chile, Vicuña Mackenna 4686, Piso 3, Macul, 7820436 Santiago, Chile

e-mail: ssolari@med.puc.cl

C. Campino · C. A. Carvajal · C. F. Lagos · A. Vecchiola ·

C. Valdivia $\cdot$ R. Baudrand · C. E. Fardella

Departamento de Endocrinología, Facultad de Medicina, Pontificia Universidad Católica de Chile, Lira 85, 5 Piso, Casilla 114-D, Santiago, Chile

C. Campino - C. A. Carvajal · R. Baudrand - G. I. Owen ·

C. E. Fardella

Instituto Milenio de Inmunología e Inmunoterapia, Avda.

Libertador Bernardo O’Higgins 340, Santiago, Chile

G. I. Owen

Departamento de Fisiología, Facultad de Ciencias Biológicas, Pontificia Universidad Católica de Chile, Avda. Libertador

Bernardo O’Higgins 340, Santiago, Chile of cortisol, cortisone, tetrahydrocortisol, allo-tetrahydrocortisol and tetrahydrocortisone was developed and validated in an LC coupled with the new detector AB Sciex QTrap $^{\circledR} 4500$ tandem mass spectrometer. The steroids were extracted from $1 \mathrm{~mL}$ urine, using cortisol-D4 as internal standard. The quantification range was $0.1-120 \mathrm{ng} / \mathrm{mL}$ for cortisol and cortisone, and $1-120 \mathrm{ng} / \mathrm{mL}$ for tetrahydrometabolites, with $>89 \%$ recovery for all analytes. The coefficient of variation and accuracy was $<10 \%$, and $85-105 \%$, respectively. Our LC-MS/MS method is accurate and reproducible in accordance with Food and Drug Administration guidelines, showing good sensitivity and recovery. This method allows the assessment of $11 \beta-H S D 2$ and $11 \beta$-HSD1 activities in a single analytical run providing an innovative tool to explain etiology of misclassified essential hypertension and/or metabolic syndrome.

Keywords Column liquid chromatography · Mass spectrometry $\cdot 11 \beta$-Hydroxysteroid dehydrogenase . Hypertension $\cdot$ Metabolic syndrome $\cdot$ Cortisol

\section{Introduction}

Cortisol homeostasis is important in controlling blood pressure, and its deregulation could be implied in hypertension and metabolic syndrome (MetS). Several enzymes modulate cortisol availability. In the liver and adipose tissue, $11 \beta$-hydroxysteroid dehydrogenase type 1 (11ß-HSD1) preferentially converts the inactive cortisone to active cortisol. In the kidney and colon, 11 $\beta$-hydroxysteroid dehydrogenase type 2 (11 $\beta$-HSD2) transforms cortisol to cortisone, protecting the mineralocorticoid receptor from erroneous activation by cortisol. Furthermore, in the liver, the $5 \alpha$ and $5 \beta$ reductases (in conjunction with $3 \alpha$-hydroxy steroid 
dehydrogenase) inactivate cortisol and cortisone to the tetrahydrometabolites: $5 \alpha$ tetrahydrocortisol, $5 \beta$ tetrahydrocortisol (allo-tetrahydrocortisol), and tetrahydrocortisone [1]. Thus, the availability of cortisol to bind and activate the glucocorticoid and mineralocorticoid receptors may be influenced by both the local pre-receptor metabolism and the systemic cortisol level.

Based on the functions of the 11 $\beta$-HSD isozymes, the impairment of their activity has been associated with the pathogenesis of arterial hypertension and MetS, which are common medical conditions. Assessing the enzymes' activities is critical to the study of these patients, where the urinary cortisol/cortisone ratio has been suggested as an index of 11 $\beta$-HSD2 activity. In the presence of a normal cortisol/ cortisone ratio, the ratio of the urinary metabolites tetrahydrocortisol and allo-tetrahydrocortisol to tetrahydrocortisone provides an estimate of $11 \beta-H S D 1$ activity $[1,2]$.

The steroid hormones in body fluids are usually measured by immunoassay in the clinical laboratory due to the simplicity, speed, and analytical sensitivity. This is possible using automated analyzers that allow high-throughput testing [3]. Despite their many advantages, immunoassays have certain limitations, including the differences between compounds cross-reactivity that are structurally related to the target, suboptimal specificity, limited dynamic range, and matrix effects [4]. Alternative techniques, such as the combination of gas chromatography and mass spectrometry (GC-MS), previously the 'gold standard' for steroid profiling, are laborious and time consuming due to the low volatility of some compounds and the need of a derivatization step, limiting their application to routine diagnostics [5]. High-performance liquid chromatography in combination with tandem mass spectrometry (LC-MS/MS) fulfills the requirements of sufficient analytical sensitivity and specificity, as well as speed and robustness, for single-steroid analysis [6, 7].

The aim of this study was to develop and validate an LC-MS/MS method, using US Food and Drug Administration (FDA) parameters for the simultaneous determination of free cortisol, cortisone, tetrahydrocortisol, allo-tetrahydrocortisol and tetrahydrocortisone in a clinical laboratory to gain a better understanding of hypertension and/or MetS pathogenesis.

\section{Materials and Methods}

Solvents and reagents

All solvents (methanol, acetone, hexane, and water) were high-performance liquid chromatography (HPLC) grade from Merck (Santiago, Chile). Formic acid (Merck) was 98-100\% pure. Cortisol (4-pregnen-11 $\beta$, 17, 21-triol-3, 20-dione), cortisol-D4 (4-pregnen-11 $\beta$, 17, 21-triol3, 20-dione-9, 11, 12, 12-d4), cortisone (4-pregnen-17, 21-diol-3, 11, 20-trione), tetrahydrocortisol (5 $\beta$-pregnan$3 \alpha, 11 \beta, 17,21$-tetrol-20-one), allo-tetrahydrocortisol (5 $\alpha$-pregnan- $3 \alpha, 11 \beta, 17,21$-tetrol-20-one), and tetrahydrocortisone (5 $\beta$-pregnan-3 $\alpha, 17,21$-triol-11-20-dione) were purchased from Steraloids, Inc., (Andover, MA, USA). Stock solutions of all standards $(1 \mathrm{mg} / \mathrm{mL})$ and of cortisolD4 as the internal standard (IS; $2 \mu \mathrm{g} / \mathrm{mL}$ ) were prepared in methanol and stored at $-20^{\circ} \mathrm{C}$.

\section{Liquid Chromatography}

The liquid chromatography separations were carried out using an Agilent Technologies Series 1200 high-pressure mixing pump equipped with a Series 1200 autosampler and microwell plate autosampler (Agilent, Boston, MA, USA). An Inertsil ODS-3 C18 (2.1 mm inner diameter $\times 150 \mathrm{~mm})$ $3-\mu \mathrm{m}$ particle size column (GL Sciences Inc., Tokyo, Japan) was used with a mobile phase gradient of solvent A (water containing $0.1 \%$ formic acid) and solvent B (methanol containing $0.1 \%$ formic acid). The gradient conditions were $0-5$ min with $40 \%$ solvent $\mathrm{A}$ and $60 \%$ solvent B, from 6 to 8 min $50 \%$ solvent $\mathrm{A}$ and $50 \%$ solvent $\mathrm{B}$, from 9 to 10 min $60 \%$ solvent $\mathrm{A}$ and $40 \%$ solvent $\mathrm{B}$, from 11 to 13 min $10 \%$ solvent $A$ and $90 \%$ solvent $B$, and from 14 to 18 min $40 \%$ solvent A and $60 \%$ solvent B.

\section{Mass Spectrometry}

An AB Sciex QTrap ${ }^{\circledR} 4500$ tandem mass spectrometer (Foster City, CA, USA) operated with a Turbo-V IonSpray source was used to obtain the mass spectra and the selected reaction monitoring (SRM) determinations. The optimized conditions were as follows: ion spray voltage, $5.5 \mathrm{kV}$; gas source 1, 60; gas source 2, 40; turbo temperature, $600{ }^{\circ} \mathrm{C}$; entrance potential, $10 \mathrm{~V}$; and declustering potential (DP), $60 \mathrm{~V}$. The collision gas pressure was set at $12 \mathrm{mPa}$ and the curtain gas pressure at $20 \mathrm{mPa}$. The SRM transitions and the related optimized DP, collision energy, and collision cell exit potential for the different analytes are shown in Table 1.

\section{Standards and Quality Control Samples}

Working solutions of eight standards $(0.1,1,5,10,30,60$, 90 and $120 \mathrm{ng} / \mathrm{mL}$ ) and three quality control samples (QCs; 20, 40 and $80 \mathrm{ng} / \mathrm{mL}$ ) were prepared in $1 \mathrm{~mL}$ steroid-free urine by dilution of the stock solution of each analyte. The standards were prepared on the day of analysis, and the QCs were prepared in bulk monthly and stored at $-20^{\circ} \mathrm{C}$.

The standards and QCs were spiked with $10 \mu \mathrm{L}$ IS (cortisol-D4; $20 \mu \mathrm{g} / \mathrm{mL}$ in methanol; final concentration, 
Table 1 LC/MS-MS data for the corticosteroids studied

\begin{tabular}{|c|c|c|c|c|c|c|}
\hline Steroid & $\begin{array}{l}\text { Molecular } \\
\text { weight (Da) }\end{array}$ & Precursor ion & $\begin{array}{l}\text { Product ions } \\
(\text { ESI }+)^{\mathrm{a}}\end{array}$ & $\begin{array}{l}\text { Declustering } \\
\text { potential }\end{array}$ & $\begin{array}{l}\text { Collision } \\
\text { energy }\end{array}$ & $\begin{array}{l}\text { Collision cell } \\
\text { exit potential }\end{array}$ \\
\hline Cortisol & 362.21 & 363.25 & $327 / 309 / \underline{121}$ & $80 / 85 / 82$ & $21 / 24 / 36$ & $16 / 14 / 10$ \\
\hline Cortisone & 360.19 & 361.24 & $343 / 301 / \underline{163}$ & $110 / 100 / 75$ & $23 / 29 / 33$ & $08 / 12 / 12$ \\
\hline Tetrahydrocortisol & 366.24 & 331.27 & $313 / \underline{301} / 295$ & $95 / 100 / 100$ & $17 / 17 / 17$ & $13 / 08 / 16$ \\
\hline Allo-tetrahydrocortisol & 366.24 & 331.27 & $313 / 295 / 271$ & $95 / 75 / 80$ & $17 / 18 / 18$ & $13 / 16 / 15$ \\
\hline Tetrahydrocortisone & 364.22 & 347.28 & $329 / 311 / \underline{243}$ & $105 / 107 / 110$ & $19 / 21 / 30$ & $16 / 18 / 13$ \\
\hline Cortisol-D4 ${ }^{\mathrm{b}}$ & 366.23 & 367.27 & $\underline{331 / 273 / 121}$ & $85 / 85 / 85$ & $24 / 24 / 36$ & $14 / 14 / 10$ \\
\hline
\end{tabular}

a Quantitative ions are underlined

${ }^{\mathrm{b}}$ Internal standard

$20 \mathrm{ng} / \mathrm{mL})$. Before analysis, steroids were extracted on SPE columns (Oasis ${ }^{\circledR}$ HLB $3 \mathrm{~mL}, 60 \mathrm{mg}$ ) preconditioned sequentially with $3 \mathrm{~mL}$ methanol and $3 \mathrm{~mL}$ water, followed by the addition of $1 \mathrm{~mL}$ urine to the columns. The columns were washed sequentially with $3 \mathrm{~mL}$ water, $3 \mathrm{~mL}$ acetone/ water $(200 \mathrm{~mL} / \mathrm{L})$, and $1 \mathrm{~mL}$ hexane. After the columns were dried by suction for $2 \mathrm{~min}$, the steroids were eluted with $2 \mathrm{~mL}$ methanol. The extracts were dried under nitrogen and dissolved in $100 \mu \mathrm{L}$ methanol/water (1:1) containing $0.1 \%$ formic acid, and $10 \mu \mathrm{L}$ samples were injected in the LC-MS/MS system.

\section{Method Validation}

The method was validated according to the FDA parameters [8]. The linearity was evaluated by the regression analysis of standards over the concentration range of the calibration curve. The lower limit of detection (LLOD) was defined as the lowest concentration of each analyte that could be reliably differentiated from background noise assessed with a blank sample; the lower limit of quantification (LLOQ) was defined as the lowest concentration that could be measured with an interday coefficient of variation (CV) of $<20 \%$ and accuracy between 80 and $120 \%$.

The precision and accuracy were assessed using the three QCs. The QCs were assayed five times within the same day for the determination of intraday precision and on five consecutive days in duplicate to determine interday precision, and the $\mathrm{CV}$ was calculated. The $\mathrm{CV}$ determined at each concentration level should not exceed $15 \%$. The accuracy was defined as the percentage of the nominal concentration and was estimated based on the percent deviation of the mean value from the target following five measurements of each of the three QCs. The mean value should be within $15 \%$ of the actual value. Calibration curves were prepared on each day of analysis.

The matrix effect (ME), recovery (RE), and process efficiency (PE) for each analyte were assessed using postextraction addition, established by Matuszewski et al. [9] and others. Briefly, three sets of standards (20, 40 and $80 \mathrm{ng} / \mathrm{mL}$ ) were prepared. Set A contained the standard and IS in methanol; set B contained extracts spiked with the standards and IS after extraction; and set C contained regular samples (i.e., urine spiked with the standards and IS before extraction). The peak area for the standards in these three sets was used to calculate ME, RE, and PE for each analyte according to the following equations:

Matrix effect $(\%)=B / A \times 100$

Recovery $(\%)=C / B \times 100$

Process efficiency $(\%)=C / A \times 100$

where $A=$ peak area of each analyte from set $\mathrm{A} ; B=$ peak area of each analyte from set $\mathrm{B}$; and $C=$ peak area of each analyte from set $\mathrm{C}$.

\section{Results}

\section{LC-MS/MS Characteristics}

The method described here allows the detection and quantification of the five free steroids in one analytical run of $18 \mathrm{~min}$, with good resolution of each analyte. The retention times for cortisone, cortisol-D4, cortisol, allo-tetrahydrocortisol, tetrahydrocortisol, and tetrahydrocortisone were $6.53,8.00,8.02,13.02,13.80$, and $14.61 \mathrm{~min}$, respectively. A representative mass chromatogram of a physiological human urine sample is shown in Fig. 1.

Linearity, Lower Limit of Detection, Lower Limit of Quantification, Precision, and Accuracy

The assay was linear from 0.1 to $120 \mathrm{ng} / \mathrm{mL}$ for cortisol and cortisone, and from 1 to $120 \mathrm{ng} / \mathrm{mL}$ for tetrahydrocortisol, allo-tetrahydrocortisol and tetrahydrocortisone. The regression coefficient $\left(r^{2}\right)$ was $>0.999$ for each of the five analytes. LLOD was $0.05 \mathrm{ng} / \mathrm{mL}$ for cortisol and cortisone, 


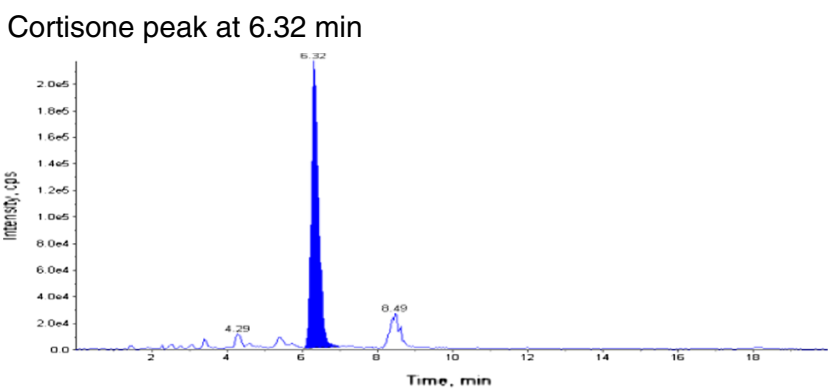

Cortisol peak at $7.90 \mathrm{~min}$

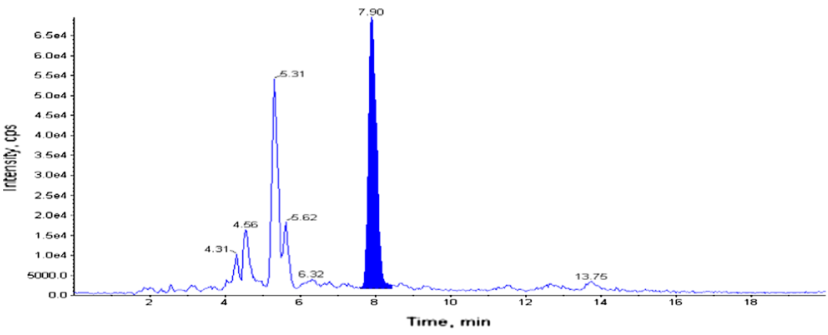

Tetrahydrocortisol peak at 13.62 min

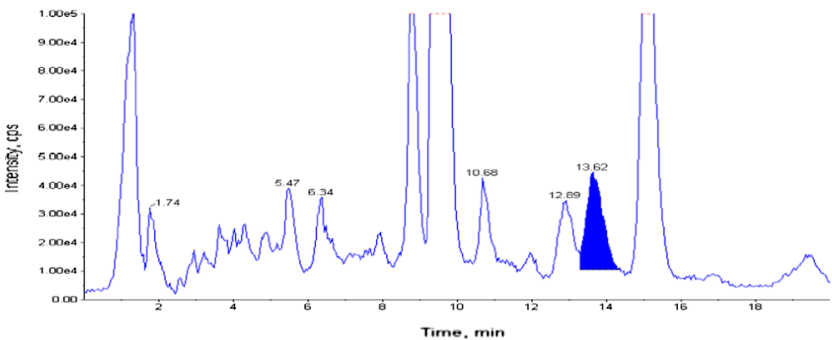

Cortisol-D4 peak at $7.87 \mathrm{~min}$

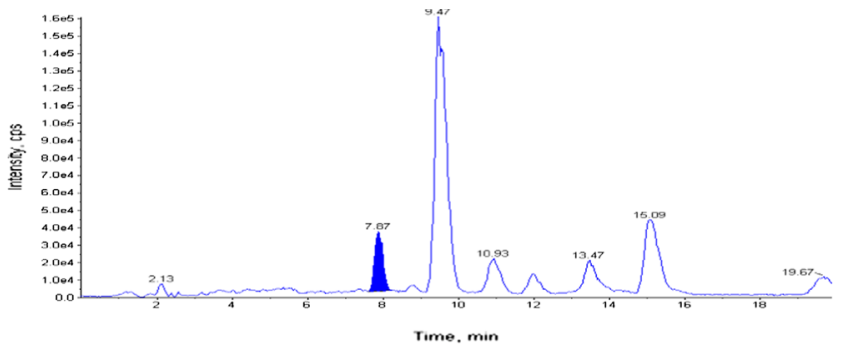

Allo-tetrahydrocortisol peak at $12.88 \mathrm{~min}$

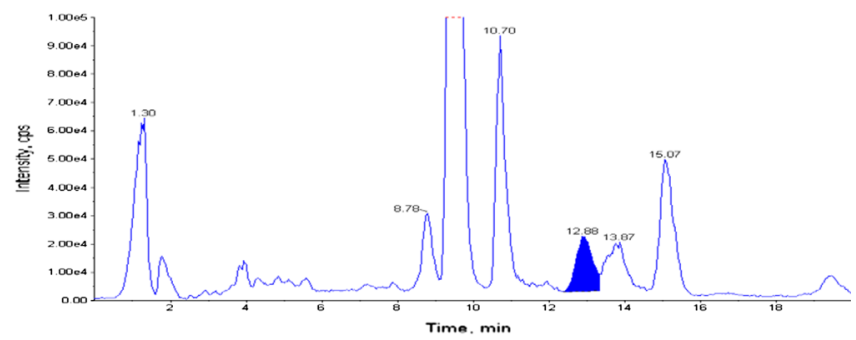

Tetrahydrocortisone peak at $14.49 \mathrm{~min}$

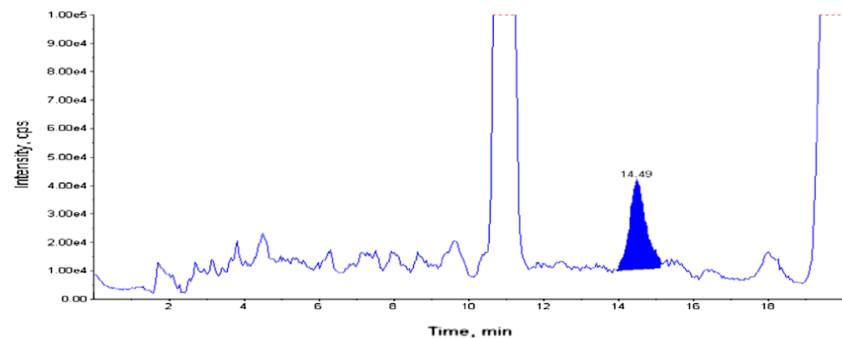

Fig. 1 Physiological human sample urine with five steroids and internal standard. Cortisone peak at 6.32 min, cortisol-D4 peak at 7.87 min, cortisol peak at $7.90 \mathrm{~min}$, allo-tetrahydrocortisol peak at $12.88 \mathrm{~min}$, tetrahydrocortisol peak at $13.62 \mathrm{~min}$, tetrahydrocortisone peak at 14.49 min

Table 2 Intraday and interday precision and accuracy in quality control pools

\begin{tabular}{|c|c|c|c|c|c|c|c|c|c|c|c|c|}
\hline \multirow[t]{2}{*}{ Steroid } & \multicolumn{4}{|c|}{$\mathrm{QC}^{\mathrm{a}} 20 \mathrm{ng} / \mathrm{mL}$} & \multicolumn{4}{|c|}{$\mathrm{QC}^{\mathrm{a}} 40 \mathrm{ng} / \mathrm{mL}$} & \multicolumn{4}{|c|}{$\mathrm{QC}^{\mathrm{a}} 80 \mathrm{ng} / \mathrm{mL}$} \\
\hline & $\begin{array}{l}\text { Mean } \\
(\mathrm{ng} / \mathrm{mL})\end{array}$ & $\mathrm{SD}^{\mathrm{b}}$ & $\mathrm{CV}^{\mathrm{c}}(\%)$ & $\begin{array}{l}\text { Accuracy } \\
(\%)\end{array}$ & $\begin{array}{l}\text { Mean } \\
(\mathrm{ng} / \mathrm{mL})\end{array}$ & $\mathrm{SD}^{\mathrm{b}}$ & $\begin{array}{l}\mathrm{CV}^{\mathrm{c}} \\
(\%)\end{array}$ & $\begin{array}{l}\text { Accuracy } \\
(\%)\end{array}$ & $\begin{array}{l}\text { Mean } \\
(\mathrm{ng} / \mathrm{mL})\end{array}$ & $\mathrm{SD}^{\mathrm{b}}$ & $\mathrm{CV}^{\mathrm{c}}(\%)$ & $\begin{array}{l}\text { Accuracy } \\
(\%)\end{array}$ \\
\hline Cortisol intraday & 20.58 & 0.58 & 2.81 & 102.9 & 39.80 & 1.00 & 2.52 & 99.5 & 83.47 & 1.09 & 1.31 & 104.34 \\
\hline Interday & 20.14 & 1.47 & 7.30 & 100.71 & 40.04 & 0.82 & 2.04 & 100.10 & 79.73 & 6.69 & 8.39 & 99.67 \\
\hline Cortisone intraday & 19.90 & 0.86 & 4.31 & 99.5 & 38.63 & 0.87 & 2.25 & 96.6 & 80.34 & 5.07 & 6.31 & 100.43 \\
\hline Interday & 20.86 & 1.89 & 9.04 & 104.32 & 38.44 & 1.24 & 3.23 & 96.10 & 80.16 & 6.84 & 8.53 & 100.20 \\
\hline $\begin{array}{l}\text { Tetrahydrocortisol } \\
\text { intraday }\end{array}$ & 20.18 & 1.04 & 5.14 & 100.9 & 38.15 & 1.86 & 4.87 & 95.4 & 76.99 & 5.42 & 7.05 & 96.23 \\
\hline Interday & 17.12 & 0.34 & 2.00 & 85.60 & 39.94 & 1.61 & 4.03 & 99.85 & 75.85 & 5.62 & 7.41 & 94.81 \\
\hline $\begin{array}{l}\text { Allo-tetrahydrocortisol } \\
\text { intraday }\end{array}$ & 18.22 & 1.38 & 7.55 & 91.1 & 35.60 & 1.44 & 4.04 & 89.0 & 73.12 & 2.68 & 3.67 & 91.40 \\
\hline Interday & 17.18 & 0.91 & 5.33 & 85.90 & 38.86 & 1.75 & 4.50 & 97.15 & 77.21 & 7.43 & 9.62 & 96.51 \\
\hline $\begin{array}{l}\text { Tetrahydrocortisone } \\
\text { intraday }\end{array}$ & 19.20 & 0.65 & 3.39 & 96.0 & 37.03 & 1.72 & 4.64 & 92.6 & 77.75 & 5.32 & 6.84 & 97.19 \\
\hline Interday & 17.94 & 0.99 & 5.53 & 89.70 & 39.46 & 1.56 & 3.95 & 98.65 & 79.69 & 6.56 & 8.23 & 99.62 \\
\hline
\end{tabular}

${ }^{\text {a }}$ Quality control

b Standard deviation

c Coefficient of variation 
Table 3 Matrix effect, recovery and efficiency of the method

${ }^{a}$ Matrix effect

b Recovery

c Performance efficiency

${ }^{d}$ Standard deviation

\begin{tabular}{|c|c|c|c|c|c|c|}
\hline \multirow[t]{2}{*}{ Steroid } & \multicolumn{2}{|c|}{$\operatorname{ME}^{\mathrm{a}}(\%)$} & \multicolumn{2}{|c|}{$\mathrm{RE}^{\mathrm{b}}(\%)$} & \multicolumn{2}{|c|}{$\operatorname{PE}^{\mathrm{c}}(\%)$} \\
\hline & Mean & $\mathrm{SD}^{\mathrm{d}}$ & Mean & $\mathrm{SD}^{\mathrm{d}}$ & Mean & $\mathrm{SD}^{\mathrm{d}}$ \\
\hline Cortisol & 91.4 & 16.1 & 101.3 & 8.9 & 91.9 & 9.3 \\
\hline Cortisone & 94.5 & 19.6 & 104.5 & 9.4 & 98.9 & 17.9 \\
\hline Tetrahydrocortisol & 76.9 & 14.4 & 99.6 & 9.4 & 75.5 & 14.3 \\
\hline Allo-tetrahydrocortisol & 122.2 & 28.5 & 95.6 & 9.4 & 115.5 & 17.9 \\
\hline Tetrahydrocortisone & 90.0 & 16.7 & 105.2 & 6.0 & 94.5 & 13.3 \\
\hline Cortisol-D4 & 95.5 & 7.3 & 90.0 & 7.8 & 85.0 & 0.9 \\
\hline
\end{tabular}

and $0.2 \mathrm{ng} / \mathrm{mL}$ for allo-tetrahydrocortisol, tetrahydrocortisol and tetrahydrocortisone, and the lowest concentration matching the LLOQ acceptance criteria was $0.1 \mathrm{ng} / \mathrm{mL}$ for cortisol and cortisone and $1.0 \mathrm{ng} / \mathrm{mL}$ for allo-tetrahydrocortisol, tetrahydrocortisol and tetrahydrocortisone.

The QCs for all five analytes had acceptable intraday and interday precision $(<10 \%)$ and accuracy $(85-105 \%)$; these results are shown in Table 2.

\section{Matrix Effect, Recovery, and Process Efficiency}

For all analytes, the mean analytical recovery was $>89 \%$, with a matrix effect ranging from 90 to $122 \%$ and a process efficiency $>76 \%$ (Table 3 ).

\section{Discussion}

We developed an analytical LC-MS/MS method for the determination of five steroids in a single analytical run that is reliable, accurate, and precise. Based on FDA regulatory guidelines [8], this method is suitable to be implemented in a clinical laboratory for routine diagnostic purposes. The assay achieved good analytical separation of all five steroids with an acceptable intraday and interday precision and accuracy. The ability to measure the five analytes over a wide analytical range, from 0.1 to $120 \mathrm{ng} / \mathrm{mL}$ for cortisol and cortisone, and $1-120 \mathrm{ng} / \mathrm{mL}$ for tetrahydrometabolites, makes this method well suited for the evaluation of $11 \beta$ HSD1 and $11 \beta$-HSD2 activity. This dynamic range broadly covers the reference values reported previously by our group [1].

Recovery and performance efficiency evaluation using Matuszewski et al. [9] procedure showed that good results were achieved for all the five steroids. Assessment of ME is mandatory in the validation of a quantitative assay using LC-MS/MS in biological samples, since endogenous impurities can affect the ionization process and may reduce or increase the efficiency of formation of the desired analyte ions. In this way, ME affects assay reproducibility and accuracy. Our study documented the absence of a significant ME, being allo-tetrahydrocortisol the one that had the largest one with a mean enhancement of $22 \%$. This could be caused by the fact that for tetrahydrometabolites the pattern of fragmentation is quite complicated, giving rise to spectra containing a large number of fragments which most of them are common to several steroid compounds [10]. For these reasons, it is necessary to separate the three tetrahydrometabolites in a successful chromatographic run prior to subsequent MS measurement. Because, in our method, allo-tetrahydrocortisol is the analyte with the least analytical sensitivity, it is the analyte that will be most affected by any loss of sensitivity and selectivity.

The use of positive or negative ionization mode was evaluated by Cuzzola et al. [11] in the only report in literature that describes the measurement of the same five steroids in human urine in a single analytical run. In this paper, the negative mode was selected for further fragmentation and quantification of the compounds. This approach was used by Turpeinen et al. [12], although this group measured only tetrahydrometabolites, and also by Pavlovic et al. [13] who were able to measure all five steroids but the method was validated in bovine urine. In our study, all the results were generated in positive ion mode and achieved a good LLOQ of $0.1 \mathrm{ng} / \mathrm{mL}$ for $\mathrm{F}$ and $\mathrm{E}$, and $1 \mathrm{ng} / \mathrm{mL}$ for the tetrahydrometabolites, although it has been reported that the negative ion mode produces better signal-to-noise ratio and reduced fragmentation than the positive ion mode [11]. Other groups have used the positive ion mode to measure cortisol and cortisone and their tetrahydrometabolites but were unable to separate the isomers tetrahydrocortisol and allo-tetrahydrocortisol [10, 14]; only Yamashita et al. [15] accomplish this issue but their method needs picolinyl derivation of cortisol and cortisone A ring metabolites.

The LLOQ achieved in our work for free steroids measurement is relevant because in urine, only a small fraction of the steroids are in the free form, with the larger fraction being conjugated to glucuronides and sulfates. The advantage of measuring free steroids is that there is no need to deconjugate the urine samples, which is time consuming and can increase the chance of inaccurate results due to incomplete hydrolysis and variability in the enzyme preparations [10]. 
The simultaneous measurement of cortisol, cortisone, tetrahydrocortisol, allo-tetrahydrocortisol, and tetrahydrocortisone will be useful in clinics and, in particular, contribute to a better understanding of the pathophysiology of essential arterial hypertension and/or MetS. The measurement of clinical diagnostic biomarkers should be reliable, robust, and suitable for high-throughput analysis. Since its introduction as a highly specialized analytical tool, LC-MS/MS has evolved into an accepted, routine diagnostic technique in the clinical laboratory. LC-MS/MS is now considered the method of choice for the measurement of steroid hormones, particularly ones that circulate at low concentrations in plasma and/or urine.

\section{Conclusions}

The LC-MS/MS method described here is accurate, precise and is in accordance with FDA guidelines. Good sensitivity, RE, and ME were obtained for the simultaneous measurement of the five analytes.

The analytical characteristics of this method make it suitable for implementation as a routine technique in the clinical laboratory, allowing the assessment of $11 \beta$-HSD1 and $11 \beta$-HSD2 activities in a single analytical run.

An adequate clinical endocrinological exam followed by the LC-MS/MS analysis of these steroids and accurate interpretation of data should aid physicians in identifying the etiology of misclassified essential hypertension and/or MetS.

Acknowledgments This work was supported by Grants from FONDEF D08I1087, FONDEF IDea CA12i10150, FONDECYT 1130427, Institute Millennium in Immunology and Immunotherapy (IMII)
P09/016-F(ICM), and Fundacion de Ciencia Translacional. supported this work. Carvajal CA and Lagos CF are fellows of the Comisión Nacional de Investigación Científica y Tecnológica de Chile.

\section{References}

1. Campino C, Carvajal CA, Cornejo J, San Martin B, Olivieri O, Guidi G, Faccini G, Pasini F, Sateler J, Baudrand R, Mosso L, Owen GI, Kalergis AM, Padilla O, Fardella CE (2009) Endocrine 37:106-114

2. Hammer F, Stewart PM (2006) Best Pract Res Clin Endocrinol Metab 20:337-353

3. Lepage R, Albert C (2006) Clin Biochem 39:542-557

4. Pujos E, Flament-Waton MM, Paisse O, Grenier-Loustalot MF (2005) Anal Bioanal Chem 381:244-254

5. Furuta T, Namekawa T, Shibasaki H, Kasuya Y (1998) J Chromatogr B Biomed Sci Appl 706:181-190

6. Vogeser M, Briegel J, Jacob K (2001) Clin Chem Lab Med 39:944-947

7. Kushnir MM, Rockwood AL, Roberts WL, Yue B, Bergquist J, Meikle AW (2011) Clin Biochem 44:77-88

8. Food and Drug Administration UDoHaHS, Center for Drug Evaluation and Research and Center for Veterinary Medicine (2001). http://www.fda.gov/downloads/Drugs/Guidances/ucm070107. pdf. Accessed 15 Oct 2013

9. Matuszewski BK, Constanzer ML, Chavez-Eng CM (2003) Anal Chem 75:3019-3030

10. Raffaelli A, Saba A, Vignali E, Marcocci C, Salvadori P (2006) J Chromatogr B Analyt Technol Biomed Life Sci 830:278-285

11. Cuzzola A, Petri A, Mazzini F, Salvadori P (2009) Rapid Commun Mass Spectrom 23:2975-2982

12. Turpeinen U, Markkanen H, Sane T, Hamalainen E (2006) Scand J Clin Lab Invest 66:147-159

13. Pavlovic R, Cannizzo FT, Panseri S, Biolatti B, Trutic N, Biondi PA, Chiesa L (2013) J Steroid Biochem Mol Biol 135:30-35

14. Saba A, Raffaelli A, Cupisti A, Petri A, Marcocci C, Salvadori P (2009) J Mass Spectrom 44:541-548

15. Yamashita K, Nakagawa R, Okuyama M, Honma S, Takahashi M, Numazawa M (2008) Steroids 73:727-737 